\title{
Serum Cytokine Concentrations in a Patient with Rheumatoid Arthritis on Etanercept Therapy Who Subsequently Developed Pneumocystis Pneumonia: A Case Report
}

\author{
Masao Sato,, ${ }^{1}$ Masao Takemura, ${ }^{2}$ Ryuki Shinohe, ${ }^{3}$ and Katsuji Shimizu1 \\ ${ }^{1}$ Department of Orthopaedic Surgery, Gifu University School of Medicine, 1-1 Yanagido Gifu, Gifu 501-1194, Japan \\ ${ }^{2}$ Department of Informative Clinical Medicine, Gifu University School of Medicine, 1-1 Yanagido Gifu, Gifu 501-1194, Japan \\ ${ }^{3}$ Department of Orthopadeic Surgery, Nishimino Welfare Hospital, 986 Oshikoshi Yoro, Gifu 503-1394, Japan
}

Correspondence should be addressed to Masao Sato, sat@air.linkclub.or.jp

Received 24 July 2011; Accepted 2 October 2011

Academic Editors: S. S. Koca, J. Mikdashi, and L. Schachna

Copyright ( $) 2011$ Masao Sato et al. This is an open access article distributed under the Creative Commons Attribution License, which permits unrestricted use, distribution, and reproduction in any medium, provided the original work is properly cited.

\begin{abstract}
We report a rheumatoid arthritis patient who was treated with etanercept. Serum levels of tumor-necrosis-factor- (TNF-) alpha, soluble-tumor-necrosis-factor receptor- (sTNFR-) I and -II, interleukin- (IL-) 6, and IL-1 beta were measured by ELISA before and during the course of therapy. While the serum levels of IL- 6 and IL-1 beta dropped rapidly following the initiation of therapy, the concentrations of TNF-alpha and sTNFR-II steadily increased to a plateau. Although significant clinical efficacy was observed, etanercept had to be discontinued when after 12 weeks of therapy the patient was found to have pneumocystis pneumonia.
\end{abstract}

\section{Introduction}

Rheumatoid arthritis (RA) is an autoimmune inflammatory disease in which cytokines, such as tumor-necrosis-factor(TNF-) alpha and interleukin- (IL-) 1, are thought to play a major role in the pathogenesis. Consequently, several publications have focused on the serum and/or synovial fluid levels of various inflammatory cytokines in patients with RA, psoriatic arthritis, and ankylosing spondylitis, with the clinical utility of such measurements being advocated $[1,2]$. Recently, TNF-alpha inhibitors have been found to induce a rapid and sustained attenuation of disease activity in patients with RA. We describe here a patient with RA treated with a TNF-alpha inhibitor, etanercept for 12 weeks before discontinuation of therapy for pneumocystis pneumonia (PCP). The serum concentrations of TNF-alpha, sTNFR-I and -II, IL-6, and IL-1 beta were measured before, during, and after etanercept therapy.

\section{Case Presentation}

A 54-year-old Japanese man who had been diagnosed with RA for 8 years according to the 1987 American Rheuma- tism Association classification criteria for RA was admitted with polyarthritis. He complained of pain and swelling in the wrists, fingers, and knees and had difficulty walking without assistance. He claimed to have morning stiffness lasting about 3 hours. Past medical history included a left total knee arthroplasty complicated by a traumatic fracture of the left distal femur postoperatively and a cerebral infarction with residual right hemiparesis. His medication regimen included sulfasalazine $(1000 \mathrm{mg} /$ day $)$, bucillamine $(300 \mathrm{mg} /$ day $)$, mizoribine $(150 \mathrm{mg} /$ day $)$, and prednisolone $(10 \mathrm{mg} /$ day). The Steinbrocker stage was IV and functional class was 4 . He was unable to stand unassisted due to bilateral knee pain. Swelling and tenderness were present in the proximal interphalangeal and metacarpophalangeal joints of both hands and fingers, as well as in the wrists and knees. Right-sided muscle weakness was observed. Laboratory findings were as follows: white blood cell count $8800 / \mathrm{mm}^{3}$ (75.6\% neutrophils, $19.5 \%$ lymphocytes, $2.9 \%$ monocytes, $0.3 \%$ eosinophils, $0.2 \%$ basophils), hemoglobin $10.7 \mathrm{mg} / \mathrm{dL}$, platelets $48.7 \times 10^{4} / \mu \mathrm{L}$, erythrocyte sedimentation rate $(\mathrm{ESR})$ $75 \mathrm{~mm} / \mathrm{h}$, C-reactive protein (CRP) $3.58 \mathrm{mg} / \mathrm{dL}$, rheumatoid factor (RF) $219.6 \mathrm{IU} / \mathrm{mL}$, and anticyclic citrullinated peptide 
antibody (ACPA) $189 \mathrm{IU} / \mathrm{mL}$. Serum $\beta$-D-glucan was negative. The purified protein derivative skin test for tuberculosis was negative.

Treatment was initiated with subcutaneous injections of etanercept $25 \mathrm{mg}$ twice a week. Blood samples were collected before the first dose (at baseline), 24 hours after the first injection (day 1), daily until day 8 , and weekly thereafter. Specimens were centrifuged at $3000 \mathrm{rpm}$ and the sera stored at $-80^{\circ} \mathrm{C}$ until the assay was performed. TNF-alpha, TNFRI and -II, IL-6, and IL-1 beta concentrations were measured using commercial ELISA kits.

After initiating etanercept, the patient's clinical condition improved markedly, with swelling and tenderness of the wrists and finger joints significantly better. He was able to stand with the aid of crutches despite residual hemiparesis. The duration of morning stiffness dropped to below 30 minutes. The 28-joint count Disease Activity Score (DAS28) dropped significantly within the first 4 weeks and continued to decrease (DAS28 $=8.09,5.37,4.73$, and 4.60 , at baseline, 4 weeks, 8 weeks, and 12 weeks, resp.), achieving the European League Against Rheumatism (EULAR) moderate response criteria. The CRP dropped to below $0.30 \mathrm{mg} / \mathrm{mL}$ within the first 2 weeks of therapy. Subsequently, the oral immunosuppressive regimen of sulfasalazine, bucillamine, and mizoribine was discontinued after initiation of treatment. Prednisolone was reduced to $5 \mathrm{mg} /$ day.

After 12 weeks of treatment with etanercept, the patient developed a nonproductive cough along with a fever of $38^{\circ} \mathrm{C}$. Serum $\beta$-D-glucan was found to be positive, and sputum polymerase chain reaction (PCR) was positive for pneumocystis (Figure 1). Etanercept was discontinued, and an antifungal regimen initiated.

Preceding etanercept therapy, the serum IL-6 levels were found to be elevated, correlating with the high CRP value and high clinical disease activity. Conversely, the serum level of TNF-alpha was nondetectable $(<0.2 \mathrm{pg} / \mathrm{mL})$; the sTNFRI, -II, and IL-1 beta values were not found to be significantly elevated (Figure 2). After initiation of etanercept, there was a rapid decline in the IL-6 and CRP levels, whereas the levels of TNF-alpha and sTNFR-II increased significantly within 24 hours after administration of the first dose to a plateau after 2 weeks (range: $100 \mathrm{pg} / \mathrm{mL}$ to $170 \mathrm{pg} / \mathrm{mL}$ ) and 6-7 weeks (range: $300 \mathrm{ng} / \mathrm{mL}$ to $700 \mathrm{ng} / \mathrm{mL}$ ), respectively. The sTNFR-I and IL-1-beta levels remained relatively unchanged (sTNFRI levels at baseline, $3.56 \mathrm{ng} / \mathrm{mL}$; 4 weeks, $3.36 \mathrm{ng} / \mathrm{mL} ; 8$ weeks, $2.93 \mathrm{ng} / \mathrm{mL} ; 12$ weeks, $3.58 \mathrm{ng} / \mathrm{mL}$ ). At week 12, concurrent to the patient developing clinical symptoms of PCP, the levels of IL-6, CRP, and TNF-alpha showed an acute peak, which tapered downward over the following 3 weeks with the institution of an appropriate antifungal regimen (Figures 3 and 4).

\section{Discussion}

Several cytokines, chemokines, and matrix metalloproteinases with serum levels that correlate with the disease activity of RA have been reported. Furthermore, a favorable clinical response following the administration of TNF-alpha

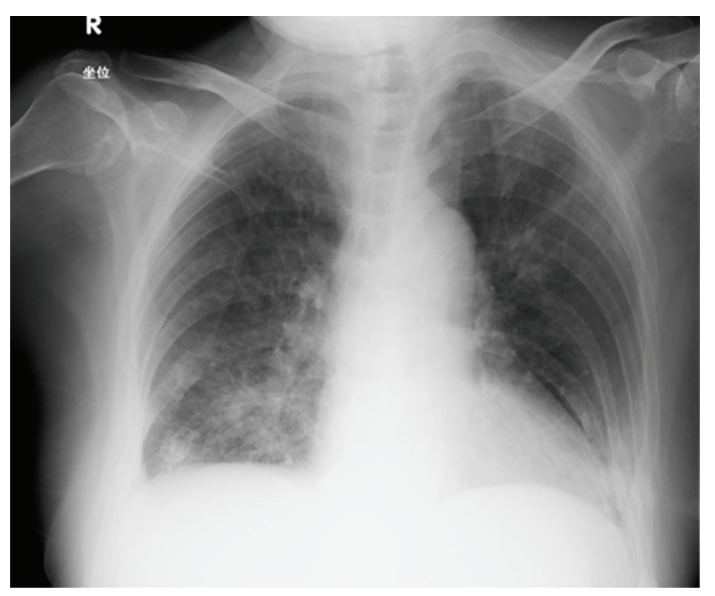

FIGURE 1: Chest radiograph revealed bilateral ground-glass infiltrates and reticular shadows.

inhibitors was shown to be accompanied by the reduced serum levels of these inflammatory mediators [3].

Etanercept is a recombinant fusion protein consisting of two p75 receptors and the Fc domain of the human IgG1 that binds to both soluble and cell-bound TNF-alpha [4]. Although etanercept is known to reduce disease activity and inhibit bone and joint destruction in patients with RA [4], it is not clear if and how etanercept modulates the serum levels of TNF-alpha, TNFR-I, and TNFR-II. We previously demonstrated that serum TNFR-II concentrations in RA patients $(n=45)$ not on biologics were significantly higher than in healthy controls $(n=80)(7.28 \pm 4.16 \mathrm{ng} / \mathrm{mL}$ versus $4.40 \pm 0.88 \mathrm{ng} / \mathrm{mL}$ ) [5]. In the patient reported here, the serum TNFR-II concentration was elevated to more than $500 \mathrm{ng} / \mathrm{mL}$ during treatment with etanercept, with return to baseline levels after discontinuation of treatment. Since etanercept is composed in part by the p75 TNF receptor, the ELISA assay might be detecting (a component of) etanercept as TNFR-II.

TNF-alpha concentrations were elevated within 24 hours of etanercept therapy in the present patient and remained high until the cessation of etanercept treatment, which supports previous reports that TNF-alpha concentrations are elevated during etanercept therapy [6]. We could explain this rise in serum TNF-alpha by the possibility that the assay might be measuring TNF-alpha that is bound to etanercept. Etanercept has an approximately 50 -fold greater affinity for human recombinant TNF-alpha in a binding inhibition assay and is approximately 1000 times more efficient than monomeric soluble TNFR. In addition, etanercept has a 5to 8 -fold longer plasma half-life compared with naturally occurring soluble TNFR. [7, 8]. Etanercept-bound TNFalpha is known to be immunoreactive although without biological activity [6]. In this case, even though TNF-alpha as measured by the ELISA was elevated during the course of treatment, disease activity was well inhibited. The levels of CRP were clearly lower during the course of treatment.

Mori et al. reported that etanercept lowered the TNFRI, IL-6, and IL-1 beta serum concentrations in juvenile idiopathic arthritis patients. The concentrations of IL- 6 at 


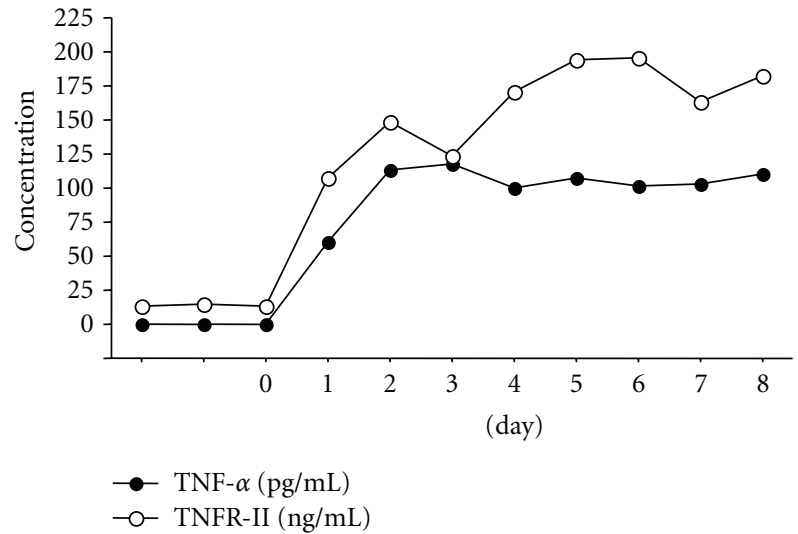

(a)

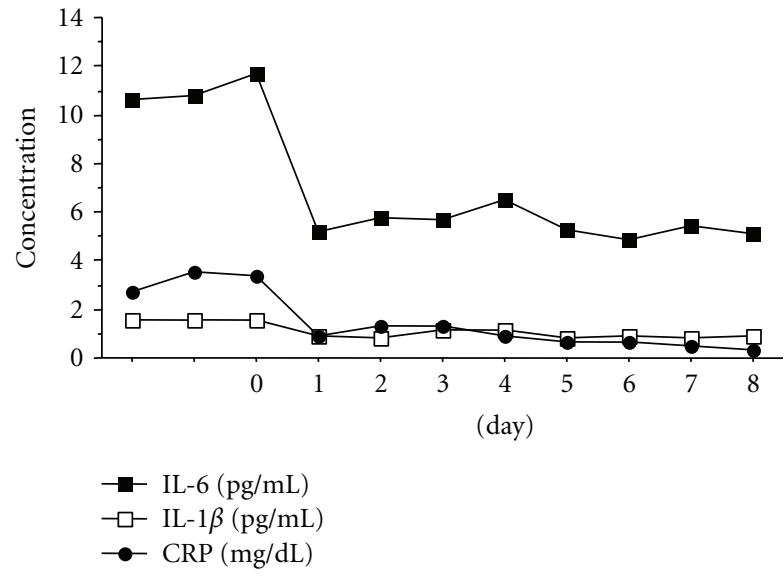

(b)

FIgURE 2: Time course of serum cytokines concentrations from baseline to 8 days. (a) TNF-alpha was not detectable in baseline samples. One day after the start of etanercept therapy TNF-alpha was measurable by ELISA. TNF-alpha levels became steady within 2 days of etanercept therapy. TNFR-II concentrations became elevated after the start of etanercept therapy. Within the first week of etanercept therapy, TNFRII reached levels ranging from $160 \mathrm{ng} / \mathrm{mL}$ to $190 \mathrm{ng} / \mathrm{mL}$. (b) Serum IL-6, IL-1 beta, and CRP concentrations were decreased just after the initiation of treatment.

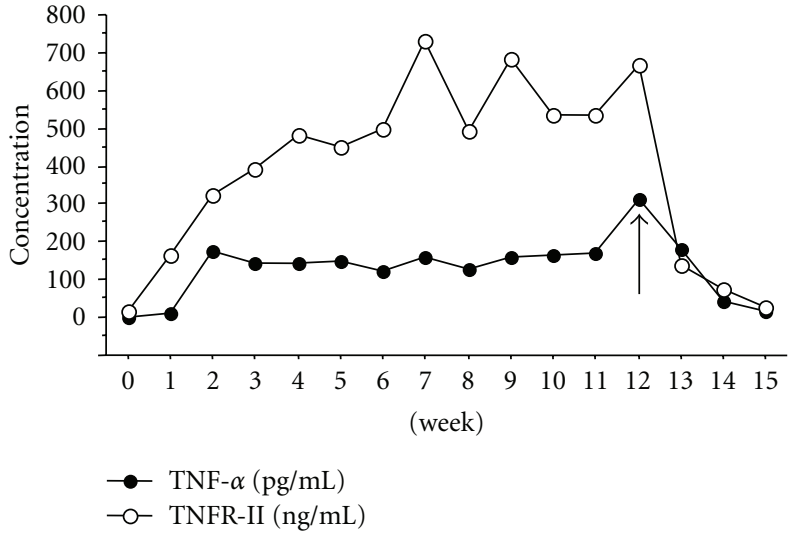

(a)

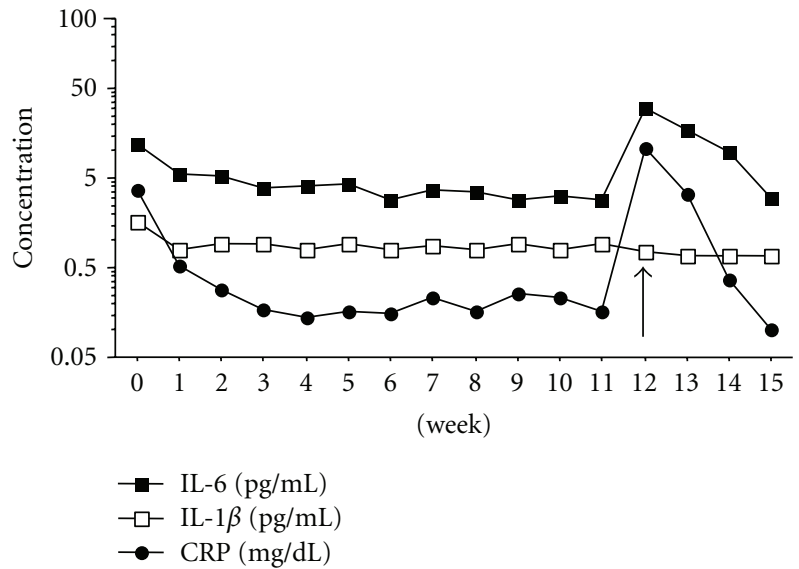

(b)

FIGURE 3: Time course of serum cytokines concentrations. (a) TNF-alpha concentration increased between weeks 1 and 2 after the initiation of etanercept therapy then remained steady ranging from $100 \mathrm{pg} / \mathrm{mL}$ to $170 \mathrm{pg} / \mathrm{mL}$. At 12 weeks, the patient developed PCP and the TNFalpha value increased steeply (arrow). With cessation of etanercept, the TNF-alpha concentration immediately returned to pretreatment levels. Four weeks after the initiation of therapy, the TNFR-II concentration became steady, ranging from $300 \mathrm{ng} / \mathrm{mL}$ to $700 \mathrm{ng} / \mathrm{mL}$. With cessation of etanercept due to the PCP, TNFR-II concentration returned to pretreatment levels. (b) On the other hand, at week 12, the levels of IL-6, CRP, and TNF-alpha showed an acute peak (arrow), which tapered downward over the following 3 weeks with the institution of an appropriate antifungal regimen.

weeks 2, 4, 8, and 12 of IL-1 beta at week 4 and of TNFRI at week 12 were significantly lower than before treatment [9]. Our data did not show remarkable changes in TNFR-I concentrations, but serum IL- 6 and IL- 1 beta concentrations were markedly decreased during the course of treatment. Trials have shown that etanercept therapy had significant clinical efficacy in patients with RA $[10,11]$. It was suggested that clinical efficacy of etanercept was due to the reduction in CRP, IL-6, and IL-1 beta concentrations.

In general, therapies using biological agents have been highly effective in the treatment of RA. However, cases with serious adverse events have also been reported. Biologics may mask the clinical symptoms of infection because they diminish the production of acute inflammatory proteins [12]. In the case discussed here, CRP and IL-6 levels were found to be elevated when the patient developed PCP. Furthermore, the serum concentration of TNF-alpha increased by more than $300 \mathrm{pg} / \mathrm{mL}$. Previously reported was a patient with high concentrations of TNF-alpha on etanercept therapy with development of gastric outlet obstruction, suggesting that serum TNF-alpha may rise in the early phase of the pneumonia, gastrointestinal obstruction, and other 


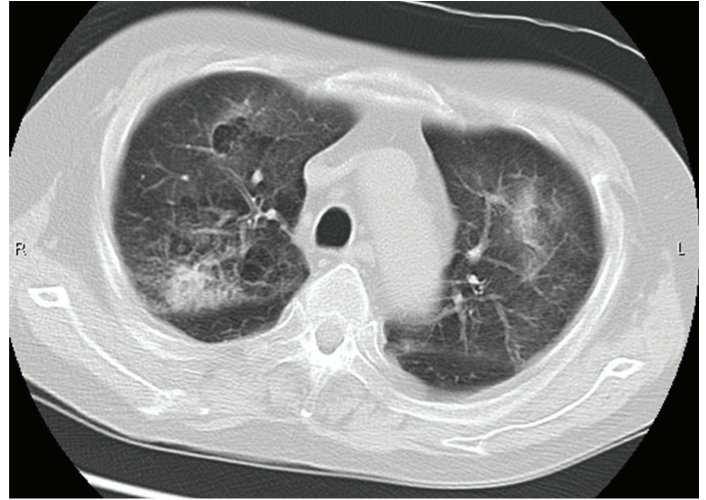

(a)

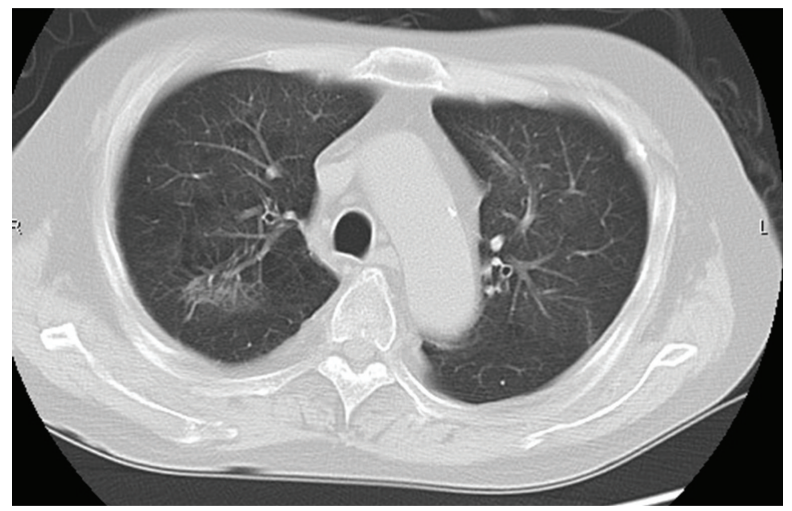

(b)

Figure 4: (a) Computed tomography scans on the day patient diagnosed as PCP showed infiltrates and reticular shadows. (b) The shadows disappeared after treatment with antifungal agents.

infectious/inflammatory complications [6]. Furthermore, we considered that endogenous TNF-alpha itself accounted for the majority of the elevated concentration of TNF-alpha at the time of pneumonia in this case. On the other hand, TNFalpha concentrations were steady after the start of etanercept therapy until the cessation of the drug. This phenomenon might demonstrate that the TNF-alpha levels reflected the proper drug dosage in the course of etanercept treatment.

In conclusion, although TNF-alpha and TNFR-II concentrations measured by ELISA might consist of the TNFetanercept complex and even etanercept itself, these concentrations could reflect the microenvironments in the course of etanercept therapy. Monitoring TNF-alpha levels might provide much information in terms of avoiding serious adverse events and evaluating clinical efficacy.

\section{References}

[1] H. Amital, V. Barak, R. E. Winkler, and A. Rubinow, "Impact of treatment with infliximab on serum cytokine profile of patients with rheumatoid and psoriatic arthritis," Annals of the New York Academy of Sciences, vol. 1110, pp. 649-660, 2007.

[2] C. Romero-Sánchez, W. H. Robinson, B. H. Tomooka et al., "Identification of acute phase reactants and cytokines useful for monitoring infliximab therapy in ankylosing spondylitis," Clinical Rheumatology, vol. 27, no. 11, pp. 1429-1435, 2008.

[3] K. L. Hyrich, K. D. Watson, A. J. Silman, D. P. M. Symmons, and The BSR Biologics Register, "Predictors of response to anti-TNF- $\alpha$ therapy among patients with rheumatoid arthritis: results from the British Society for Rheumatology Biologics Register," Rheumatology, vol. 45, no. 12, pp. 1558-1565, 2006.

[4] M. Feldmann, "Development of anti-TNF therapy for rheumatoid arthritis," Nature Reviews Immunology, vol. 2, no. 5, pp. 364-371, 2002.

[5] M. Sato, M. Takemura, R. Shinohe et al., "Soluble tumor necrosis factor receptor levels in sera and joint fluids of rheumatoid arthritis patients," Rinsho Riumachi, vol. 15, pp. 313-318, 2003 (Japanese).

[6] S. Madhusedan, M. Foster, S. R. Muthuramalingam et al., "A phase II study of etanercept (Enbrel), a tumor necrosis factor a inhibitor in patients with metastatic brest cancer," Clinical Cancer Research, vol. 10, pp. 6528-6534, 2004.

[7] L. W. Moreland, M. H. Schiff, S. W. Baumgartner et al., "Etanercept therapy in rheumatoid arthritis: a randomized, controlled trial," Annals of Internal Medicine, vol. 130, no. 6, pp. 478-486, 1999.

[8] A. Alldred, "Etanercept in rheumatoid arthritis," Expert Opinion on Pharmacotherapy, vol. 2, no. 7, pp. 1137-1148, 2001.

[9] M. Mori, S. Takei, T. Imagawa et al., "Pharmacokinetics, efficacy, and safety of short-term (12 weeks) etanercept for methotrexate-refractory polyarticular juvenile idiopathic arthritis in Japan," Modern Rheumatology, vol. 15, no. 6, pp. 397-404, 2005.

[10] L. Klareskog, D. van der Heijde, J. P. de Jager et al., “Therapeutic effect of the combination of etanercept and methotrexate compared with each treatment alone in patients with rheumatoid arthritis: double-blind randomised controlled trial," The Lancet, vol. 363, no. 9410, pp. 675-681, 2004.

[11] D. van der Heijde, L. Klareskog, V. Rodriguez-Valverde et al., "Comparison of etanercept and methotrexate, alone and combined, in the treatment of rheumatoid arthritis: two-year clinical and radiographic results from the TEMPO study, a double-blind, randomized trial," Arthritis \& Rheumatism, vol. 54, no. 4, pp. 1063-1074, 2006.

[12] N. Miyasaka, T. Takeuchi, and K. Eguchi, "Guidelines for the proper use of etanercept in Japan," Modern Rheumatology, vol. 16, no. 2, pp. 63-67, 2006. 


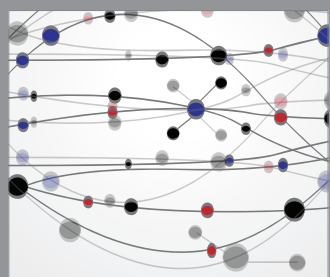

The Scientific World Journal
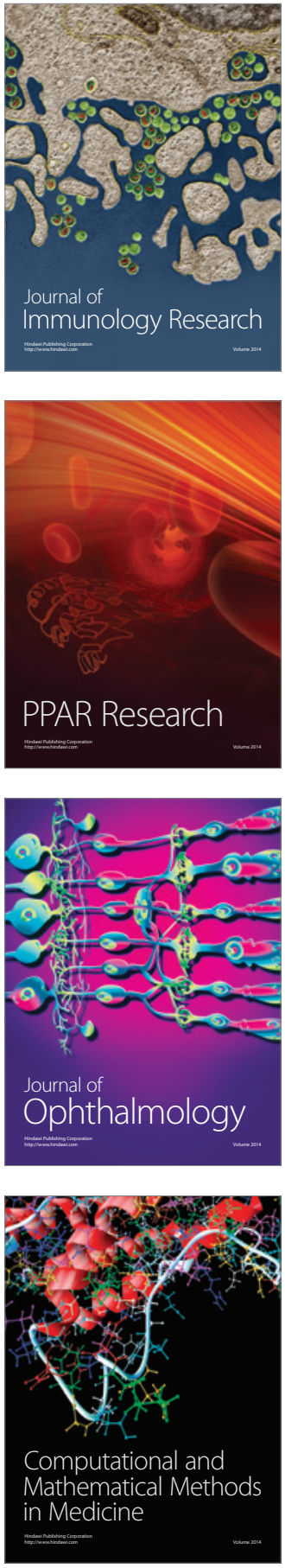

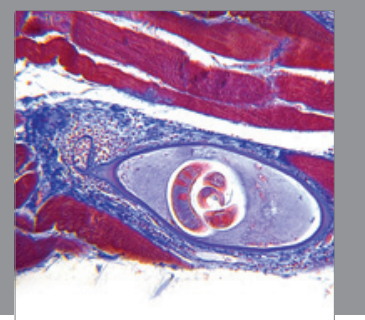

Gastroenterology

Research and Practice
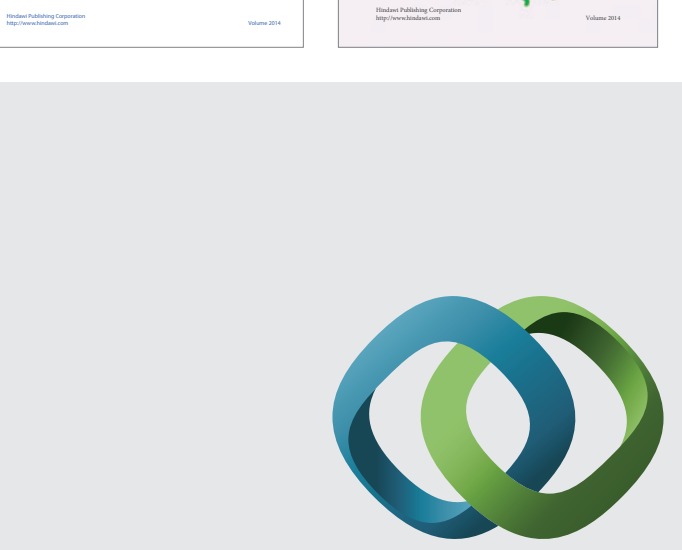

\section{Hindawi}

Submit your manuscripts at

http://www.hindawi.com
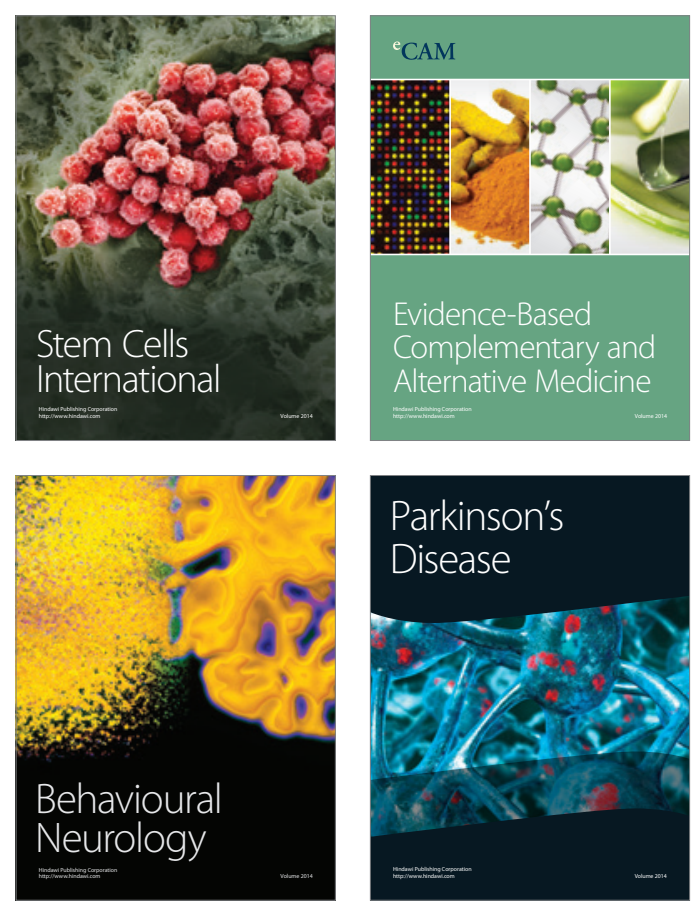

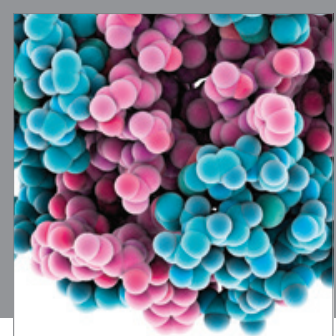

Journal of
Diabetes Research

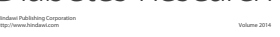

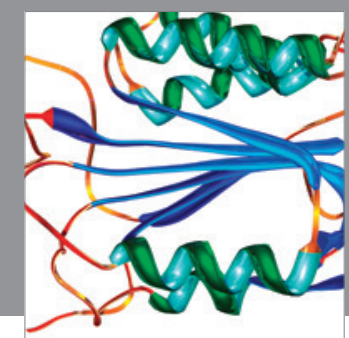

Disease Markers
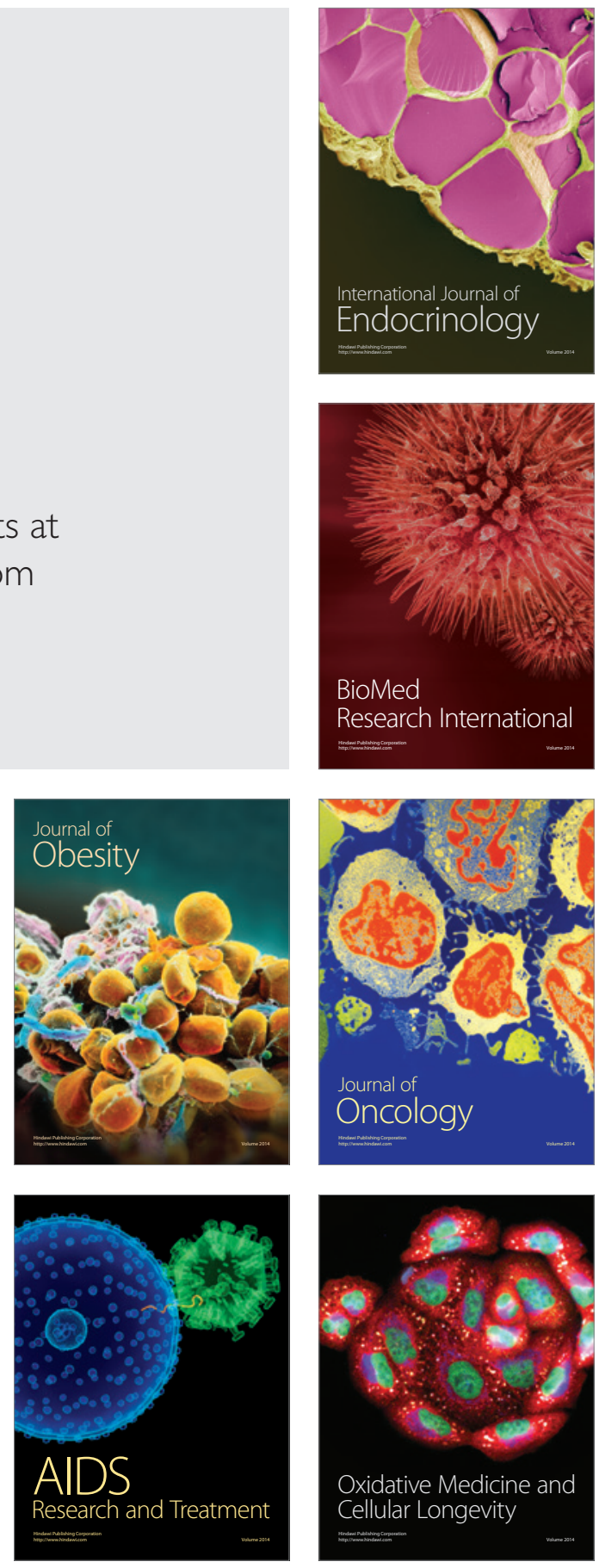